\title{
The Reeded Edge and the Phillips Curve: Money Neutrality, Common Knowledge, and Subjective Beliefs*
}

\author{
Michael Suk-Young Chwe \\ Department of Economics, University of Chicago, \\ 1126 East 59th Street, Chicago, Illinois 60637 \\ michael@chwe.net
}

Received February 2, 1998; revised March 4, 1999

\begin{abstract}
I present a simple two-person auction model in which a seller and a buyer make bids in terms of money; however, the value of a unit of money is uncertain. I show: (1) a monetary revaluation has purely nominal effects if and only if it is common knowledge; (2) if seller and buyer have identical beliefs, making the value of money common knowledge maximizes total gains from trade; (3) if seller and buyer are equally well informed and have identical beliefs, then monetary revaluations have no net effect; (4) when the seller knows the value of money but the buyer does not, the expected utilities of both seller and buyer are proportional to $1 /\left(1+\sigma^{2}\right)$, where $\sigma$ is the standard deviation of the value of money expressed as a fraction of the mean; and (5) when beliefs are subjective, monetary policy can improve total gains from trade, as in Friedman's explanation of the Phillips curve, and an optimal level of inflation can be determined. Journal of Economic Literature Classification Numbers: C78, E52. (C) 1999 Academic Press
\end{abstract}

\section{INTRODUCTION}

Presumably the exact value of a unit of money is arbitrary, just as the exact mass of a kilogram is arbitrary. But in practice, revaluing money is taken for granted as a way to influence real economic outcomes. Lucas [19] approached this by assuming that individuals cannot distinguish exactly between a change in the value of money and a change in real conditions; hence nominal changes can have real effects. Using models of incom-

* This paper has benefitted greatly from the comments of participants in the NSF-NBER Decentralization Conference at the University of Illinois, Champaign-Urbana and at seminars at Indiana University Purdue University at Indianapolis, Northwestern University, Southern Methodist University, and the University of Chicago. I especially appreciate the encouragement and suggestions of John Cochrane, Lars Hansen, Larry Jones, Jim Jordan, Bob Lucas, Rody Manuelli, Stephen Morris, Tom Sargent, Lars Stole, Dimitri Vayanos, Steve Williams, Mike Woodford, the students in my graduate game theory classes, and an anonymous referee for this journal who was exceptionally helpful. 
plete information was advocated early on by Phelps [26], but since then, incomplete information in trade has been analyzed more often in microeconomic contexts.

This paper presents a simple two person auction model in which a seller and buyer make bids in units of money; however, the value of a unit of money, the rate at which money is redeemed into utility, is uncertain. The model is flexible enough so that beliefs and the kind of incomplete information can be specified freely, as if they were policy variables rather than structural features of the economy.

The first result is that a monetary revaluation has purely nominal effects if and only if it is common knowledge in the game theoretic sense: everyone knows about the revaluation, everyone knows that everyone knows, and so on. In other words, the informational requirements for neutrality are strong: a monetary revaluation can have real effects even if everyone knows about it, for example. Evidence suggests that knowledge of other people's knowledge takes longer to form than knowledge; this is one possible mechanism by which a revaluation can have persistent effects. This result also suggests that for a "regime change" to have no real effects, it would have to be publicized and understood widely enough as to be common knowledge.

The second result is that if seller and buyer have the same beliefs, making the value of a unit of money common knowledge maximizes total expected utility. This helps explain the marking of the edges of coins in response to the problem of incremental shaving, or "clipping." Edge marking, which culminated in the "reeded edge," made a coin's value not just certain but also common knowledge, which maximizes total gains when the coin is used in trade. This result also suggests that given identical beliefs, an optimal monetary policy would keep the value of money absolutely certain.

The third result is that if buyer and seller are equally well informed about the world and have the same beliefs, then monetary revaluations have no net effect. In other words, informational asymmetry is necessary for monetary policy to have nontrivial effects.

The fourth result is for the example in which the seller knows the value of money but the buyer does not, and beliefs are identical. A linear equilibrium can be solved explicitly, and we can compute the welfare losses due to monetary uncertainty: the expected utilities of both seller and buyer are proportional to $1 /\left(1+\sigma^{2}\right)$, where $\sigma$ is the standard deviation of the value of money expressed as a percentage of the mean. This is a possible reason why people use cash for exchange instead of interest bearing securities, which are more volatile; even if I know exactly what a given security is worth, I lose if I have to trade with someone who does not.

Finally, I show that if the seller and buyer have different, "subjective", beliefs, then monetary policy can improve total gains from trade, measured 
objectively. Thus a possible justification for an interventionist monetary policy is that in the presence of subjective beliefs, it can help reduce trading inefficiencies due to incomplete information. I find an optimal level of inflation which captures the intuition that low levels of inflation encourage trade but high levels render money useless in trade. Subjective beliefs can be thought of as resulting from differently anticipated money revaluations, for example if an employer expects a revaluation but a worker does not, as in Friedman's [12] explanation of the Phillips curve. The Phillips curve as a transitory phenomenon thus can be understood naturally in the model.

Here money is modelled through the auction mechanism: money is what people bid in. By assuming that a unit of money has a (possibly uncertain) value, big questions such as how and why money has value, as well as how the total amount of money in an economy relates to the value of each unit, are assumed away. For example, monetary devaluation and money neutrality are understood here not in terms of the money supply but in terms of the value of a unit of money. This paper is not about money's necessary attributes or how it emerges endogenously; rather, I assume that money has a value and look at the effects of changing it.

\section{AN AUCTION MODEL WITH BIDS IN MONEY}

Say a seller sells a single indivisible object to a buyer: the seller values the object at $v_{s}$, and the buyer values the object at $v_{b}$. The valuations $v_{s}$ and $v_{b}$ are distributed uniformly and independently over the interval $[0,1]$. Each person knows her own valuation, but knows only the distribution of the other's valuation. An example of this bilateral uncertainty might be two people bargaining over a used car, in which the buyer does not know what it would take for the seller to part with it, and the seller does not know how much the buyer really wants it. In a macroeconomic context (as in Friedman [12]), the seller would be a worker selling his labor, and the buyer would be a factory owner buying labor. They bargain over the wage: the worker does not know how much the factory owner needs his labor, and the factory owner does not know how much the worker needs the job. Total employment, or output, would simply be total gains from trade.

If the buyer bids higher than the seller, trade takes place at a price halfway between the two bids; if the buyer bids lower than the seller, no trade takes place and neither the seller or buyer gains or loses anything. This split-the-difference trading mechanism is called a $k$-double auction, where $k=1 / 2$.

Money is freely redeemable into utility, but the "redemption rate", the value of a unit of money in utility terms, is uncertain. I model it as a positive real-valued random variable, which is a function $m: \Omega \rightarrow(0, \infty)$. 
Here $\Omega$ is the set of possible states of the world, assumed finite and nonempty (for simplicity we think of $\Omega$ as incorporating uncertainty over money only, not over valuations). At state of the world $\omega \in \Omega$, the redemption rate is $m(\omega)$ : we call the function $m$ the "redemption rule". The seller's beliefs over $\Omega$ are given by the probability distribution $\pi_{s}: \Omega \rightarrow[0,1]$, and the buyer's beliefs are given by $\pi_{b}: \Omega \rightarrow[0,1]$.

What each person knows about the state of the world is represented by a partition of $\Omega$; the seller's "knowledge partition" is $\mathscr{P}_{s}$ and the buyer's is $\mathscr{P}_{b}$. Given $\omega \in \Omega$, let $P_{s}(\omega)$ be the element of $\mathscr{P}_{s}$ which contains $\omega$ and $P_{b}(\omega)$ be the element of $\mathscr{P}_{b}$ which contains $\omega$. The idea here is that when the state of the world is $\omega$, all the seller knows is that the state of the world is contained in the set $P_{s}(\omega)$ (similarly for the buyer).

This is the complete description of the model $\Gamma\left(\Omega, \pi_{s}, \pi_{b}, \mathscr{P}_{s}, \mathscr{P}_{b}, m\right): \pi_{s}$ and $\pi_{b}$ are the prior distributions over the states of the world $\Omega, \mathscr{P}_{s}$ and $\mathscr{P}_{b}$ are the knowledge partitions, and $m$ is the redemption rule; as usual, all of these things are assumed to be common knowledge among the two players. We assume that $\sum_{\omega \in P_{s}} \pi_{s}(\omega)>0$ for all $P_{s} \in \mathscr{P}_{s}$ and $\sum_{\omega \in P_{b}} \pi_{b}(\omega)>0$ for all $P_{b} \in \mathscr{P}_{b}$ : the seller believes that all events in $\mathscr{P}_{s}$ occur with positive probability ( similarly for the buyer).

Given the state of the world $\omega$ and his valuation $v_{s}$, the seller bids $s\left(\omega, v_{s}\right)$. But remember that the seller does not necessarily know the state $\omega$; all he knows is that the state is in $P_{s}(\omega)$, and he cannot distinguish between states in $P_{s}(\omega)$. Hence, $s$ must be constant over $P_{s}(\omega)$. Thus, we define a strategy for the seller to be a function $s: \Omega \times[0,1] \rightarrow \Re$ that is measurable with respect to the partition $\mathscr{P}_{s}$; in other words, for all $\omega_{1}, \omega_{2} \in \Omega$, if $P_{s}\left(\omega_{1}\right)=P_{s}\left(\omega_{2}\right)$, then $s\left(\omega_{1}, v_{s}\right)=s\left(\omega_{2}, v_{s}\right)$ for all $v_{s} \in[0,1]$. Similarly, a strategy for the buyer is a function $b: \Omega \times[0,1] \rightarrow \Re$ that is measurable with respect to $\mathscr{P}_{b}$.

Given the players' strategies $s$ and $b$, we calculate the players' (ex ante) expected utilities:

$$
\begin{aligned}
E U_{s}(s, b)= & \sum_{\omega \in \Omega} \iint_{\left\{\left(v_{s}, v_{b}\right) \in[0,1]^{2}: b\left(\omega, v_{b}\right) \geqslant s\left(\omega, v_{s}\right)\right\}} \pi_{s}(\omega) \\
& \times\left(m(\omega) \frac{s\left(\omega, v_{s}\right)+b\left(\omega, v_{b}\right)}{2}-v_{s}\right) d v_{s} d v_{b} \\
E U_{b}(s, b)= & \sum_{\omega \in \Omega} \iint_{\left\{\left(v_{s}, v_{b}\right) \in[0,1]^{2}: b\left(\omega, v_{b}\right) \geqslant s\left(\omega, v_{s}\right)\right\}} \pi_{b}(\omega) \\
& \times\left(v_{b}-m(\omega) \frac{s\left(\omega, v_{s}\right)+b\left(\omega, v_{b}\right)}{2}\right) d v_{s} d v_{b} .
\end{aligned}
$$


As usual, a strategy pair is an equilibrium if neither player can gain by deviating.

Definition. The strategy pair $(s, b)$ is an equilibrium of $\Gamma\left(\Omega, \pi_{s}, \pi_{b}\right.$, $\left.\mathscr{P}_{s}, \mathscr{P}_{b}, m\right)$ if $s$ is a strategy for the seller, $b$ is a strategy for the buyer, and $E U_{s}(s, b) \geqslant E U_{s}\left(s^{\prime}, b\right)$ for all strategies for the seller $s^{\prime}$, and $E U_{b}(s, b) \geqslant$ $E U_{b}\left(s, b^{\prime}\right)$ for all strategies for the buyer $b^{\prime}$.

This framework is Aumann's [2] correlated equilibrium; the key idea is that a person's strategy is a function from state of the world to action which is measurable with respect to her information partition. The state of the world $\omega$ is usually considered as purely informational and not directly entering into utility functions, as it does here through money, but this is a minor extension. The auction literature (for example Linhart, Radner, and Satterthwaite [18]) usually requires that a person's bid must maximize expected utility for every possible valuation, as opposed to a bid function maximizing ex ante expected utility averaged over all valuations. This is really a matter of interpretation, whether different valuations correspond to different people or different realizations for the same person. Doing everything in ex ante terms makes it easy to remain compatible with the correlated equilibrium framework.

\section{MONEY NEUTRALITY}

Intuitively, money neutrality means that changing the value of a unit of money has only nominal effects. Here we attempt a definition. Say the redemption rule is $m$, the seller's strategy is $s$ and the buyer's strategy is $b$; we can then express the strategies $s$ and $b$ in real terms.

Definition. Given strategies $s: \Omega \times[0,1] \rightarrow \mathfrak{R}$ and $b: \Omega \times[0,1] \rightarrow \mathfrak{R}$, the functions $[s]$ and $[b]$ are the equivalent real strategies, where $[s]$ : $\Omega \times[0,1] \rightarrow \mathfrak{R}$ and $[b]: \Omega \times[0,1] \rightarrow \mathfrak{R}$ are defined as $[s]\left(\omega, v_{s}\right)=$ $m(\omega) s\left(\omega, v_{s}\right)$ and $[b]\left(\omega, v_{b}\right)=m(\omega) b\left(\omega, v_{b}\right)$.

In state of the world $\omega$, a unit of money is worth $m(\omega)$. Given strategies $s$ and $b$, which are in terms of the money unit, one puts them in real terms by simply multiplying by $m(\omega)$ for each $\omega \in \Omega$. Now the definition of neutrality is simple.

Definition. Given $\Gamma\left(\Omega, \pi_{s}, \pi_{b}, \mathscr{P}_{s}, \mathscr{P}_{b}, m\right)$, the redemption rule $m$ is neutral if $(s, b)$ is an equilibrium of $\Gamma\left(\Omega, \pi_{s}, \pi_{b}, \mathscr{P}_{s}, \mathscr{P}_{b}, m\right)$ if and only if $([s],[b])$ is an equilibrium of $\Gamma\left(\Omega, \pi_{s}, \pi_{b}, \mathscr{P}_{s}, \mathscr{P}_{b}, \bar{m}\right)$, where $\bar{m}$ is the constant function $\bar{m}(\omega)=1$. 
In other words, the redemption rule $m$ is neutral if the resulting set of equilibria are different only nominally from the set of equilibria in the "no policy" case, in which the redemption rule is the constant function $\bar{m}$. Every equilibrium with $m$ is just the nominal rescaling of an equilibrium with $\bar{m}$, and every equilibrium with $\bar{m}$, suitably rescaled, is an equilibrium with $m$. When the redemption rule $m$ is neutral, it is easy to show that expected utilities and the probability of trade in an equilibrium are exactly those which could be obtained in an equilibrium in the "no policy" case. Hence a neutral redemption rule $m$ has no real effects.

\section{COMMON KNOWLEDGE}

An event is common knowledge when everyone knows it, everyone knows that everyone knows it, and so on without limit (Aumann [3]). Remember that if the state of the world is $\omega \in \Omega$, then the seller knows that the state of the world is in $P_{s}(\omega)$, where $P_{s}(\omega)$ is the element in the seller's knowledge partition $\mathscr{P}_{s}$ which contains $\omega$ (similarly for the buyer). Also, remember that an event is represented as a subset $E$ of $\Omega$. Given a particular state of the world $\omega \in \Omega$, then, we say that given $\omega$ the seller knows the event $E$ if $P_{s}(\omega) \subset E$ (again, similarly for the buyer).

With this in mind we can think of a person knowing an event $E$ as an event itself. Let $K_{s}(E)$ be a subset of $\Omega$, defined as $K_{s}(E)=\{\omega \in \Omega$ : $\left.P_{s}(\omega) \subset E\right\}$ (the set $K_{b}(E)$ is defined similarly). Now the definition of common knowledge is easy to understand.

Definition. The event $E \subset \Omega$ is common knowledge given state $\omega \in \Omega$ if $\omega \in K_{i_{1}}\left(K_{i_{2}}\left(K_{i_{3}}\left(\cdots K_{i_{l}}(E) \cdots\right)\right)\right)$ for all finite sequences $i_{1}, i_{2}, \ldots, i_{l} \in\{s, b\}$.

\section{MONEY NEUTRALITY IS EQUIVALENT TO COMMON KNOWLEDGE}

Which monetary policies are neutral? Given $y \in(0, \infty)$, the set $m^{-1}(\{y\})=\{\omega \in \Omega: m(\omega)=y\}$ is simply the event that the redemption rate is $y$. The following result says that the redemption rule $m$ is neutral if and only if whenever the redemption rate is $y$, it is common knowledge that the redemption rate is $y$.

Proposition 1. Say we have $\Gamma\left(\Omega, \pi_{s}, \pi_{b}, \mathscr{P}_{s}, \mathscr{P}_{b}, m\right)$. The redemption rule $m$ is neutral if and only if for all $y \in(0, \infty)$, the event $m^{-1}(\{y\}) \subset \Omega$ is common knowledge given $\omega$ for all $\omega \in m^{-1}(\{y\})$. 
The proof is almost trivial and follows directly from our definitions (all proofs are in the appendix). To illustrate it, say that $m^{-1}(\{3\})$, the event that money is worth 3 , is not common knowledge for all states $\omega \in m^{-1}(\{3\})$. Then it is easy to show from the definition of common knowledge above that there must exist some $\omega^{*} \in m^{-1}(\{3\})$ such that either $P_{s}\left(\omega^{*}\right)$ or $P_{b}\left(\omega^{*}\right)$ is not contained in $m^{-1}(\{3\})$. Say that $P_{s}\left(\omega^{*}\right)$ is not contained in $m^{-1}(\{3\})$, as shown in Fig. 1. At state $\omega^{*}$, all the seller knows is that the true state of the world is in $P_{s}\left(\omega^{*}\right)$, and thus cannot distinguish between state $\omega^{*}$, in which case money is worth 3 , and for example state $\omega^{* *}$, in which case money is worth 4 . Because she cannot distinguish between these two states, the seller must pursue the same nominal bidding strategy at states $\omega^{*}$ and $\omega^{* *}$. Hence in real terms she bids lower in state $\omega^{*}$, where money is worth 3 , and higher in state $\omega^{* *}$, where money is worth 4 . Hence monetary policy is not neutral.

If $m^{-1}(\{y\})$ is common knowledge for all states $\omega \in m^{-1}(\{y\})$, then one can show (Aumann [3]) that $m^{-1}(\{y\})$ is the union of some elements of $\mathscr{P}_{s}$ and also the union of some elements of $\mathscr{P}_{b}$ (in other words, $m^{-1}(\{y\}) \in$ $\mathscr{P}_{s} \wedge \mathscr{P}_{b}$, the "meet" or finest common coarsening of $\mathscr{P}_{s}$ and $\left.\mathscr{P}_{b}\right)$. Hence situations like Fig. 1 never happen, and the seller and buyer can always adjust their nominal bidding strategies to take into account monetary revaluations.

This result shows that the informational requirements for money neutrality are strict. It is not enough that everyone knows about a revaluation; I have to know that you know it, you have to know that I know it, I have to know that you know that I know it, an so on.

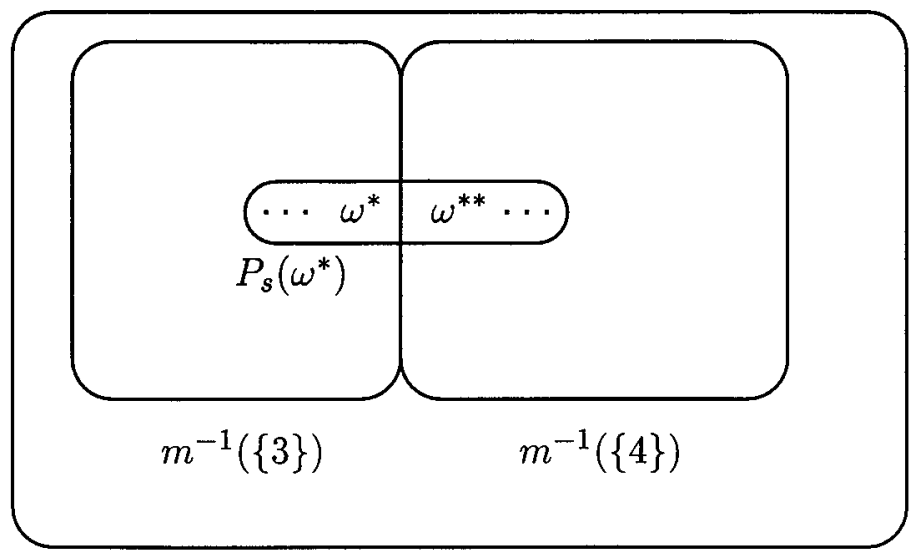

FIG. 1. The event that money is worth $3, m^{-1}(\{3\})$, is not common knowledge at $\omega^{*}$; hence money is not neutral. 
One common objection to the idea that monetary policy works through incomplete information is that monetary policy seems to have persistent, long lasting effects, while incomplete information can in principle be resolved very quickly. The result here might help reconcile this, simply because it is more difficult for something to become common knowledge than to simply become widely known. The closest thing to empirical evidence on this issue comes from sociological studies of "pluralistic ignorance", in which people have incorrect beliefs about the beliefs of others (O'Gorman [25]). In 1988, for example, 83 percent of Israeli citizens supported a written constitution, but among the minority who did not, 73 percent believed that their opinion was the majority opinion (Shamir [33]). In Israel in 1988, there was a "liberal bias": people believed that others' opinions were more liberal than they really were. The classic studies of pluralistic ignorance in the United States in the 1960s and 1970s (for example O'Gorman [24]) found a "conservative bias"; people believed that others' opinions were more conservative than they really were. Shamir [33] notes that this can be understood as people slowly realizing that others' opinions are changing: in 1988 Israeli popular opinion was moving rightward and in the 1960s and 1970s US popular opinion was moving leftward. How these results might apply to the macroeconomic context (involving beliefs about actual events rather than beliefs about people's opinions) is not obvious, but at least one might say that correct beliefs about other people's beliefs cannot be presumed to form overnight.

Another way to estimate the difficulty of common knowledge formation is to see how much it costs. Solving coordination problems such as Britain's currency decimalization and Sweden's change from driving on the left to driving on the right requires intense and costly marketing campaigns; recently, for example, roughly $\$ 1$ billion was spent on worldwide advertising introducing the computer operating system Windows 95 (Auerbach and Crosariol [1]). To solve a coordination problem, one must not only inform everyone, but also inform everyone that everyone else is informed (Chwe $[8,9]$ ). Announcements by the Federal Reserve chairman are publicized, but not nearly to this hegemonic extent; hence they can still have real effects. Sargent [30, p. 121] describes four historical illustrations of how "a government could eliminate inflation very rapidly and with virtually no Phillips curve costs in terms of foregone real output or increased unemployment. The 'measure' that would accomplish this would be a once-and-for-all, widely understood and widely agreed upon change in the monetary or fiscal policy regime." The result here suggest that "widely understood" should include the notion of common knowledge. Even if everyone is convinced of the inevitability and permanence of a regime change, some people might believe that others are doubtful; a regime change might thus be undermined even though everyone believes in it. 
Even when a fact becomes in some sense very close to common knowledge, behavior can be quite different from when the fact is common knowledge (Rubinstein [28]; see also Monderer and Samet [20], Morris, Rob, and Shin [22], and Shin [35]). In a model by Shin [34], searching for a trading partner is a coordination problem, since your probability of meeting a partner depends on the search intensity of others as well as your own; hence you will search a lot only if other people do also. Even when everyone knows that the fundamental conditions of the economy are good and support trade, when this fact is not common knowledge, trade is greatly diminished: since I do not know that you know that conditions are good, I suspect that you might not search very much, and this leads me to search less, and so on.

In any case, the result suggests that monetary policy is not just about money itself but also how people know about it and know about others' knowledge. This might help explain how a public statement by the Federal Reserve might have a different effect from more privately circulated information, for example (see Goodfriend [13]). It also suggests looking at how communications media affect people's knowledge of the knowledge of others, by for example publishing the results of public opinion polls. People's knowledge is determined not only by the availability of information but also its cost; Jones and Manuelli [16] consider a buyer and seller who each chose whether to become informed, at some cost, about monetary policy, thereby endogenizing the particular form of incomplete information.

\section{WHEN MONEY IS COMMON KNOWLEDGE}

Say that at state $\omega$, it is common knowledge that money is worth $m(\omega)$. It turns out that $s\left(\omega, v_{s}\right)=(1 / m(\omega))\left(1 / 4+2 v_{s} / 3\right)$ and $b\left(\omega, v_{b}\right)=$ $(1 / m(\omega))\left(1 / 12+2 v_{b} / 3\right)$ is an equilibrium, which Chatterjee and Samuelson [7] call the "linear equilibrium". A great variety of equilibria exist, including equilibria in which strategies are solutions to differential equations (Satterthwaite and Williams [31]) as well as equilibria in which strategies are discontinuous (Leininger, Linhart, and Radner [17]). The linear equilibrium, however, among all equilibria, maximizes total expected gains from trade. In fact, there is no other equilibrium of any other trading mechanism which performs better (Myerson and Satterthwaite [23]). It also has some support from laboratory experiments (Radner and Schotter [27]).

For example, say that at state $\omega$, it is common knowledge that money is worth $m(\omega)=1$ (the simplest example of this is when $\Omega=\{\omega\}, \pi_{s}(\omega)=$ $\pi_{b}(\omega)=1$ and $\left.\mathscr{P}_{s}=\mathscr{P}_{b}=\{\{\omega\}\}\right)$. The linear equilibrium strategies are 

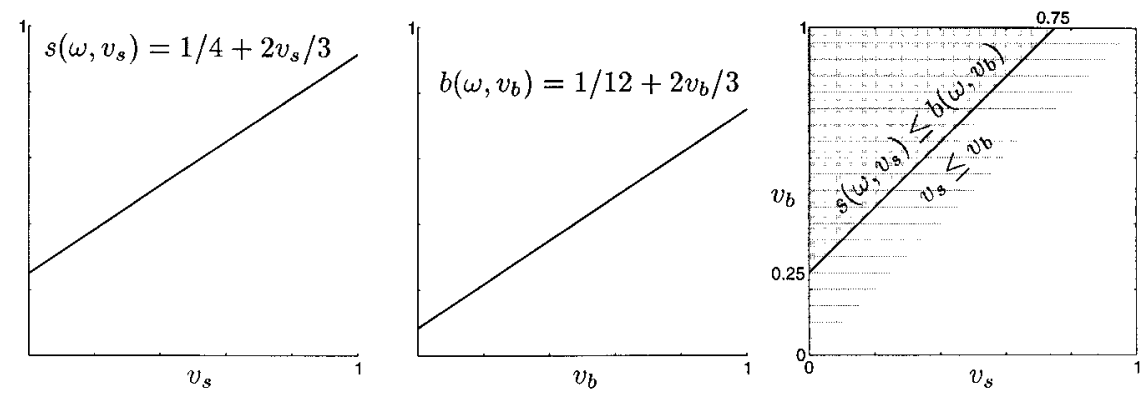

FIG. 2. Linear equilibrium strategies and the trade region when $m(\omega)=1$ is common knowledge at $\omega$.

shown in Fig. 2. Trade occurs when $s\left(\omega, v_{s}\right) \leqslant b\left(\omega, v_{b}\right)$, shown by the shaded region. Ideally, trade should take place whenever $v_{s} \leqslant v_{b}$, shown by the striped region. There is a substantial region in which trade "should" occur but does not.

Ideally, trade should occur with an ex ante probability of $1 / 2=0.500$, that is, whenever $v_{s} \leqslant v_{b}$, and total expected gains from trade would be $1 / 6 \approx 0.167$. In the linear equilibrium, however, the ex ante probability of trade is only $9 / 32 \approx 0.281$, and the seller and buyer each have an ex ante expected utility of $9 / 128 \approx 0.070$, yielding total expected gains from trade of $9 / 64 \approx 0.141$. There is a substantial gap, typical of models of trade with incomplete information, between what one might hope to achieve (the "first best") and what is possible given that players are necessarily strategic (the "second best").

\section{COMMON KNOWLEDGE MAXIMIZES WELFARE}

Is it possible to tune monetary uncertainty so as to increase total expected utility? Not as long as priors $\pi_{s}$ and $\pi_{b}$ are equal.

Proposition 2. Say $(s, b)$ is an equilibrium of $\Gamma\left(\Omega, \pi_{s}, \pi_{b}, \mathscr{P}_{s}, \mathscr{P}_{b}, m\right)$, where $\pi_{s}=\pi_{b}$. Then $E U_{s}(s, b)+E U_{b}(s, b) \leqslant 9 / 64$.

The proof uses a general mechanism design approach: given equal beliefs, the incentive compatibility constraints of the mechanism design problem with money uncertainty, when "summed together" over all states, imply the incentive compatibility constraints of the mechanism design problem without money uncertainty; hence the results of Myerson and Satterthwaite [23] apply.

Money uncertainty (with identical priors) cannot make things better. This result supports a stable, unvarying monetary policy. It also supports 
the argument that one reason money exists is because gains are maximized when trade is in terms of a good which has a certain value (see also for example Banerjee and Maskin [5] and Williamson and Wright [38]).

Again, it is not enough that both seller and buyer know what a unit of money is worth; it has to be common knowledge. A simple illustration of this comes from coin-making technology. A perpetual problem with early coins was "clipping", in which people shave incremental and unnoticeable slivers off a coin, pass the coin off in trade, and keep the slivers (Doty [11]). By making the worth of a given coin uncertain, clipping obviously inhibited trade. The technological response was to mark a coin's edge, both on the coin's two faces and directly on the coin's edge. The height of this development in terms of effectiveness and ease of production, and a remnant on today's fiat-money coins, is the serrated or "reeded" edge.

The problem of uncertainty in coin value could have been solved by everyone owning an accurate scale (less convenient, but more decentralized); everyone would know exactly the worth of a given coin. But regardless of the accuracy of your own scale, short of widespread certification you would never be sure of the accuracy of your trading partner's scale. For example, a buyer might suspect that the seller suspects that the buyer's coin is worth less than its true value, and thus the buyer might be reluctant to use the coin in exchange. In such a situation, both seller and buyer would know what the coin is worth, but it would not be common knowledge. With the reeded edge, however, one can say, "Look at this coin; I see what it is worth, and I also know that you can see what it is worth". The reeded edge made the value of the coin not just individually but also publicly verifiable, that is, common knowledge.

\section{WHEN PEOPLE HAVE THE SAME INFORMATION AND BELIEFS, MONEY HAS NO NET EFFECT}

There is a case in which money has real effects but no "net" real effects: when the seller and buyer have the same knowledge partition $\left(\mathscr{P}_{s}=\mathscr{P}_{b}\right)$ and beliefs $\left(\pi_{s}=\pi_{b}\right)$. Then the seller and buyer both bid in terms of the average redemption rate. That is, if a unit of money is worth $2 / 3$ with probability $1 / 2$ and $4 / 3$ with probability $1 / 2$, and neither knows its actual value, they both bid as if a unit of money is worth 1 with certainty.

Proposition 3. Say we have $\Gamma\left(\Omega, \pi_{s}, \pi_{b}, \mathscr{P}_{s}, \mathscr{P}_{b}, m\right)$, where $\pi_{s}=\pi_{b}=\pi$ and $\mathscr{P}_{s}=\mathscr{P}_{b}$. Then $(s, b)$ is an equilibrium of $\Gamma\left(\Omega, \pi_{s}, \pi_{b}, \mathscr{P}_{s}, \mathscr{P}_{b}, m\right)$ if and only if $(s, b)$ is an equilibrium of $\Gamma\left(\Omega, \pi_{s}, \pi_{b}, \mathscr{P}_{s}, \mathscr{P}_{b}, m^{\text {avg }}\right)$, where $m^{\text {avg }}$ is defined by $m^{\text {avg }}(\omega)=\left(\sum_{\omega^{\prime} \in P_{s}(\omega)} \pi\left(\omega^{\prime}\right) m\left(\omega^{\prime}\right)\right) /\left(\sum_{\omega^{\prime} \in P_{s}(\omega)} \pi\left(\omega^{\prime}\right)\right)$. 
For example, say $\Omega=\left\{\omega_{1}, \omega_{2}\right\}, \quad \mathscr{P}_{1}=\mathscr{P}_{2}=\left\{\omega_{1}, \omega_{2}\right\}, \quad m\left(\omega_{1}\right)=2 / 3$, $m\left(\omega_{2}\right)=4 / 3$, and $\pi\left(\omega_{1}\right)=\pi\left(\omega_{2}\right)=1 / 2$. Again, half the time money is worth $2 / 3$ and half the time it is worth $4 / 3$, and neither seller nor buyer knows when. The linear equilibrium is $s\left(\omega_{1}, v_{s}\right)=s\left(\omega_{2}, v_{s}\right)=1 / 4+2 v_{s} / 3, b\left(\omega_{1}, v_{b}\right)$ $=b\left(\omega_{2}, v_{b}\right)=1 / 12+2 v_{b} / 3$. On average money is worth 1 , and both seller and buyer bid as if money had a commonly known value of 1 in both states. Hence total expected gains from trade is $9 / 64$, as in the common knowledge case. In state $\omega_{1}$ the seller's expected utility is $3 / 128$ and the buyer's expected utility is $15 / 128$; in state $\omega_{2}$ the seller's expected utility is $15 / 128$ and the buyer's expected utility is $3 / 128$. Money uncertainty does have real effects: when money is cheap, the buyer gains at the seller's expense, and when money is expensive, the seller gains at the buyer's expense. But these effects average out.

\section{THE SELLER KNOWS AND THE BUYER DOES NOT}

Another example in which it is possible to write down equilibrium strategies explicitly is when the seller always knows the state of the world and the buyer never does. So let $\mathscr{P}_{s}=\{\{\omega\}: \omega \in \Omega\}$ and $\mathscr{P}_{b}=\{\Omega\}$, and assume identical beliefs $\pi=\pi_{s}=\pi_{b}$. Let $E(m)=\sum_{\omega \in \Omega} \pi(\omega) m(\omega)$ and $E\left(m^{2}\right)=\sum_{\omega \in \Omega} \pi(\omega)(m(\omega))^{2}$, and say $\sigma^{2}=\left(E\left(m^{2}\right)-(E(m))^{2}\right) /(E(m))^{2}$; in other words, $\sigma$ is the standard deviation of the redemption rate expressed as a fraction of the mean. As long as there is not too much monetary variation $\left(m(\omega) \leqslant(4 / 3) E(m)\left(1+\sigma^{2}\right)\right.$ for all $\left.\omega \in \Omega\right)$, a linear equilibrium uniquely exists, given by

$$
\begin{aligned}
& s\left(\omega, v_{s}\right)=\frac{1}{4 E(m)\left(1+\sigma^{2}\right)}+\frac{2}{3 m(\omega)} v_{s} \\
& b\left(\omega, v_{b}\right)=\frac{1}{E(m)\left(1+\sigma^{2}\right)}\left(\frac{1}{12}+\frac{2}{3} v_{b}\right) .
\end{aligned}
$$

The seller knows the state $\omega$ and hence his strategy depends on it: when the redemption rate $m(\omega)$ is high, when money is expensive, then the seller bids lower, more aggressively. The buyer's strategy is constant in the state $\omega$ because she never knows what it is. Compared to the "no policy" case in which there is no variation in the redemption rate and thus $\sigma^{2}=0$, the buyer bids lower, that is, less aggressively. The seller's and the buyer's expected utility are both $E U_{s}=E U_{b}=(9 / 128)\left(1 /\left(1+\sigma^{2}\right)\right)$, which is less for both than when money is common knowledge; monetary uncertainty hurts both sides. 
Taking a simple example, let $\Omega=\left\{\omega_{1}, \omega_{2}\right\}, m\left(\omega_{1}\right)=2 / 3, m\left(\omega_{2}\right)=4 / 3$, and $\pi_{s}\left(\omega_{1}\right)=\pi_{s}\left(\omega_{2}\right)=\pi_{b}\left(\omega_{1}\right)=\pi_{b}\left(\omega_{2}\right)=1 / 2$. Hence $E(m)=1$ and $\sigma^{3}=1 / 9$. We graph equilibrium strategies and the resulting region of trade (the shaded region) in Fig. 3 below. The seller and buyer both end up with expected utility $81 / 1280 \approx 0.063$, ten percent less than the common knowledge $9 / 128 \approx 0.070$. For the sake of comparison, the equilibrium strategies and trading region for the "no policy" case, in which $m\left(\omega_{1}\right)=$ $m\left(\omega_{2}\right)=1$, are indicated by dotted lines.

In state $\omega_{1}$, money is worth less than average and hence the seller bids higher, that is, more reluctantly: he knows that if he sells the good, the money he gets from the sale will not be worth very much. In state $\omega_{1}$, trade occurs with probability $27 / 160 \approx 0.169$, much lower than the "no policy" $9 / 32 \approx 0.281$, and occurs only when the seller values the object very little. Expected utilities in state $\omega_{1}$ are $81 / 3200 \approx 0.025$ for the seller and $243 / 3200 \approx 0.076$ for the buyer; since money is cheap, the buyer gets a good deal, and the seller a bad deal, relative to the "no policy" $9 / 128 \approx 0.070$.

$\omega_{1}$
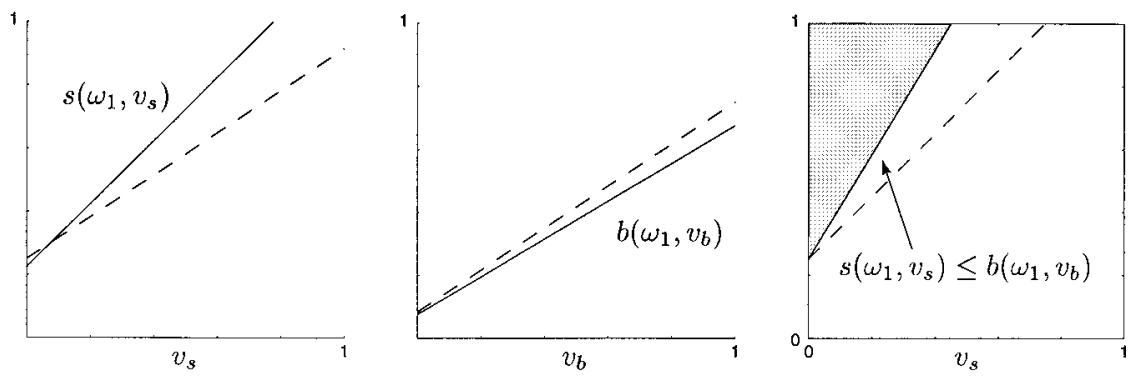

$\omega_{2}$
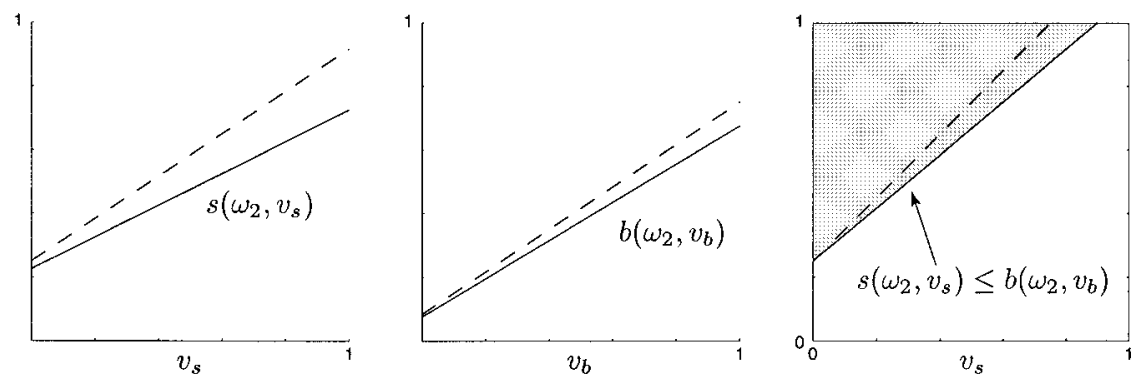

FIG. 3. Equilibrium strategies and trade regions when $\Omega=\left\{\omega_{1}, \omega_{2}\right\}, \mathscr{P}_{s}=\left\{\left\{\omega_{1}\right\},\left\{\omega_{2}\right\}\right\}$, $\mathscr{P}_{b}=\left\{\left\{\omega_{1}\right\},\left\{\omega_{2}\right\}\right\}, m\left(\omega_{1}\right)=2 / 3, m\left(\omega_{2}\right)=4 / 3, \pi\left(\omega_{1}\right)=1 / 2$ and $\pi\left(\omega_{2}\right)=1 / 2$. Dotted lines indicate the "no policy" case. 
In state $\omega_{2}$, however, the seller bids lower, that is, more aggressively. Here the seller knows that money is worth more than average and is thus anxious for a sale in which he comes away with some cash; trade occurs with probability $27 / 80 \approx 0.338$, much higher than in the "no policy" case. Expected utilities in state $\omega_{2}$ are $81 / 800 \approx 0.101$ for the seller and $81 / 1600 \approx 0.051$ for the buyer; since money is worth a lot, the seller enjoys a substantial premium.

To summarize, here money uncertainty has sometimes a bad and sometimes a good effect for both buyer and seller. But on average the bad outweighs the good.

\section{OBJECTIVE WELFARE GAINS FROM SUBJECTIVE BELIEFS}

Friedman [12] interpreted the Phillips curve by saying that employers first become aware of a monetary devaluation and offer only nominally higher wages, inducing the less well-informed workers to work more. Eventually workers find out about the devaluation also, making the increase in output transitory.

Our model fits this story by modelling unanticipated changes with the seller's and buyer's prior beliefs, again where the seller is the worker selling his labor and the buyer is a factory owner buying labor. An unanticipated change is thought of here as an event which has a prior probability of zero. If the buyer anticipates a revaluation and the seller does not, for example, this would correspond to the seller and buyer having different, or "subjective", prior beliefs. With subjective beliefs and the right kind of "surprise", it turns out that a revaluation can increase total gains from trade measured objectively.

For example, let $\Omega=\left\{\omega_{1}, \omega_{2}, \omega_{3}\right\}$, let $\mathscr{P}_{s}=\left\{\left\{\omega_{1}, \omega_{2}\right\},\left\{\omega_{3}\right\}\right\}$, and let $\mathscr{P}_{b}=$ $\left\{\left\{\omega_{1}\right\},\left\{\omega_{2}\right\},\left\{\omega_{3}\right\}\right\}$. Let the redemption rule be $m\left(\omega_{1}\right)=1, m\left(\omega_{2}\right)=$ $m\left(\omega_{3}\right)=5 / 6$; money is revalued in the event $\left\{\omega_{2}, \omega_{3}\right\}$, corresponding to a 20 percent inflation rate. Say the priors are $\pi_{s}\left(\omega_{1}\right)=2 / 3, \pi_{s}\left(\omega_{2}\right)=0, \pi_{s}\left(\omega_{3}\right)$ $=1 / 3$, and $\pi_{b}\left(\omega_{1}\right)=\pi_{b}\left(\omega_{2}\right)=\pi_{b}\left(\omega_{3}\right)=1 / 3$. Here the buyer knows everything about the state of the world and knows exactly when the revaluation occurs. The seller, however, cannot always tell when the revaluation occurs. She knows about the revaluation in the state $\omega_{3}$; otherwise, she believes that the revaluation takes place with probability zero. The state $\omega_{2}$ is in this sense unanticipated by the seller.

If we compute linear equilibrium strategies, we get $s\left(\omega_{1}, v_{s}\right)=s\left(\omega_{2}, v_{s}\right)=$ $1 / 4+2 v_{s}+3, \quad s\left(\omega_{3}, v_{s}\right)=(6 / 5)\left(1 / 4+2 v_{s} / 3\right)$, and $b\left(\omega_{1}, v_{b}\right)=1 / 12+2 v_{b} / 3$, $b\left(\omega_{2}, v_{b}\right)=1 / 12+(6 / 5)\left(2 v_{b} / 3\right), b\left(\omega_{3}, v_{b}\right)=(6 / 5)\left(1 / 12+2 v_{b} / 3\right)$. These strategies and the corresponding trade regions are shown in Fig. 4. Again, dotted lines indicate the "no policy" case in which $m\left(\omega_{1}\right)=m\left(\omega_{2}\right)=m\left(\omega_{3}\right)=1$. 

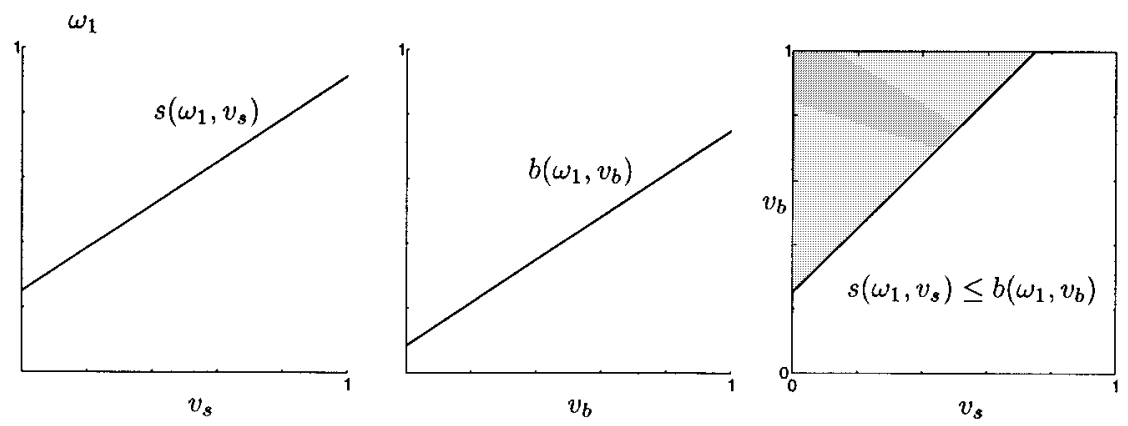

$\omega_{2}$
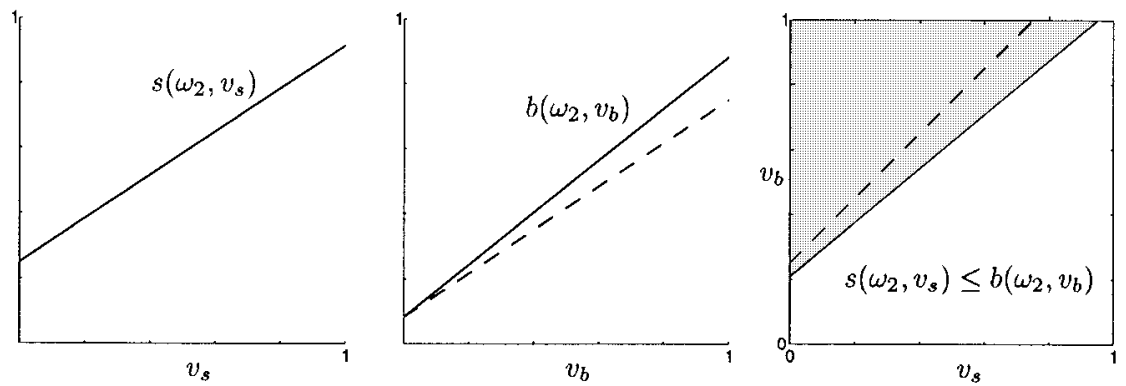

$\omega_{3}$
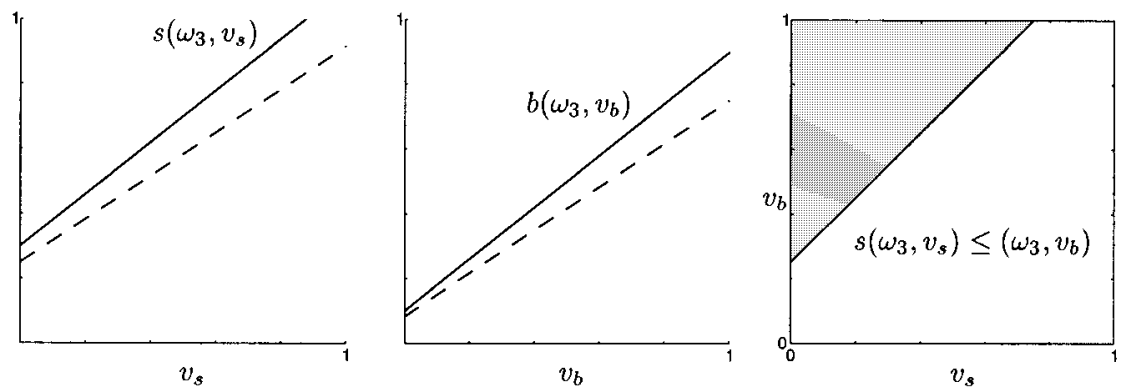

FIG. 4. Equilibrium strategies and trade regions when $\Omega=\left\{\omega_{1}, \omega_{2}, \omega_{3}\right\}, m\left(\omega_{1}\right)=1$, $m\left(\omega_{2}\right)=m\left(\omega_{3}\right)=5 / 6, \quad \mathscr{P}_{s}=\left\{\left\{\omega_{1}, \omega_{2}\right\}, \quad\left\{\omega_{3}\right\}\right\}, \quad \mathscr{P}_{b}=\left\{\left\{\omega_{1}\right\}, \quad\left\{\omega_{2}\right\}, \quad\left\{\omega_{3}\right\}\right\}, \quad \pi_{s}\left(\omega_{1}\right)=2 / 3$, $\pi_{s}\left(\omega_{2}\right)=0, \pi_{s}\left(\omega_{3}\right)=1 / 3$, and $\pi_{b}\left(\omega_{1}\right)=\pi_{b}\left(\omega_{2}\right)=\pi_{b}\left(\omega_{3}\right)=1 / 3$. Dotted lines indicate the "no policy" case.

It is easy to interpret these results: in state $\omega_{3}$, the redemption rate is common knowledge and hence we have the common knowledge strategies. In states $\omega_{1}$ and $\omega_{2}$, the seller does not know whether it is $\omega_{1}$ or $\omega_{2}$, but believes for certain that it is $\omega_{1}$. Hence he believes the redemption rate is 1 for sure, and simply plays the "no policy" strategy. In $\omega_{1}$, the buyer knows that the revaluation has not taken place and plays the "no policy" 
strategy. In $\omega_{2}$, the buyer knows that money is cheap and hence bids more aggressively.

When we calculate expected utilities in each state of the world, we naturally get the common knowledge values except at $\omega_{2}$, for which we have $E U_{s}\left(\omega_{2}\right) \approx 0.058$ and $E U_{b}\left(\omega_{2}\right) \approx 0.099$. In state $\omega_{2}$, in which the buyer knows about the revelation but the seller is caught unawares, the seller loses but the buyer gains by more, which increases the total gains from trade to 0.158 , more than 10 percent over the common knowledge value of 0.141 . We can also see from the figure that the region of trade expands significantly.

Calculating ex ante total expected utility would involve deciding which prior, $\pi_{s}, \pi_{b}$, or some other 'objective' prior, is the appropriate one. However, total expected utility is unaffected or improved in every state; hence ex ante total expected utility is improved, or at least not diminished, regardless of the prior. This is not a "Dutch book" phenomenon, in which two people have different subjective beliefs about the likelihood of an event and it is thus possible to design a bet which gives both arbitrarily high subjective expected utility. Here, total expected utility is increased or unchanged in all states of the world and is in this sense an "objective" phenomenon. (This result does depend on the assumption that the revaluation is a complete surprise to the seller: if $\pi_{s}\left(\omega_{2}\right)$ were some small positive number instead of zero, then total expected utility in $\omega_{2}$ would be significantly above the common knowledge value, but total expected utility in $\omega_{1}$ would be slightly less than the common knowledge value; still, under any "objective" prior which assigns sufficiently small probability to $\omega_{1}$, the gains from $\omega_{2}$ would outweigh the losses in $\omega_{1}$.)

Another way to see that this is not a Dutch book phenomenon is that expected utilities cannot be made arbitrarily high. Consider now an arbitrary revaluation; that is, let $m\left(\omega_{2}\right)$ be any positive number (we still have $m\left(\omega_{1}\right)=1$ and $\left.m\left(\omega_{3}\right)=m\left(\omega_{2}\right)\right)$. As before, in the states $\omega_{1}$ and $\omega_{3}$, we have the common knowledge strategies and outcome. Total expected utility in state $\omega_{2}$ is shown in Fig. 5 . (For $m\left(\omega_{2}\right)<4 / 5$, the buyer's equilibrium strategy in state $\omega_{2}$ is linear for low $v_{b}$ and constant for high $v_{b}$; although this is not a linear function, it is appropriate for the sake of comparison.)

Total expected utility in state $\omega_{2}$ (and hence ex ante) is maximized when $m\left(\omega_{2}\right)=22 / 31$, which corresponds to roughly a 41 percent devaluation; this might be thought of as an "optimal" rate of inflation. Total expected utility in state $\omega_{2}$ rises to $121 / 744 \approx 0.163$, which is close to the first best $1 / 6 \approx 0.167$. In this example, monetary policy, in a fleeting state of the world at least, can go a significant way toward reducing trade inefficiencies due to incomplete information.

Note that expected gains from trade are reduced if the revaluation is extreme in either direction. If money becomes more expensive (deflation), 


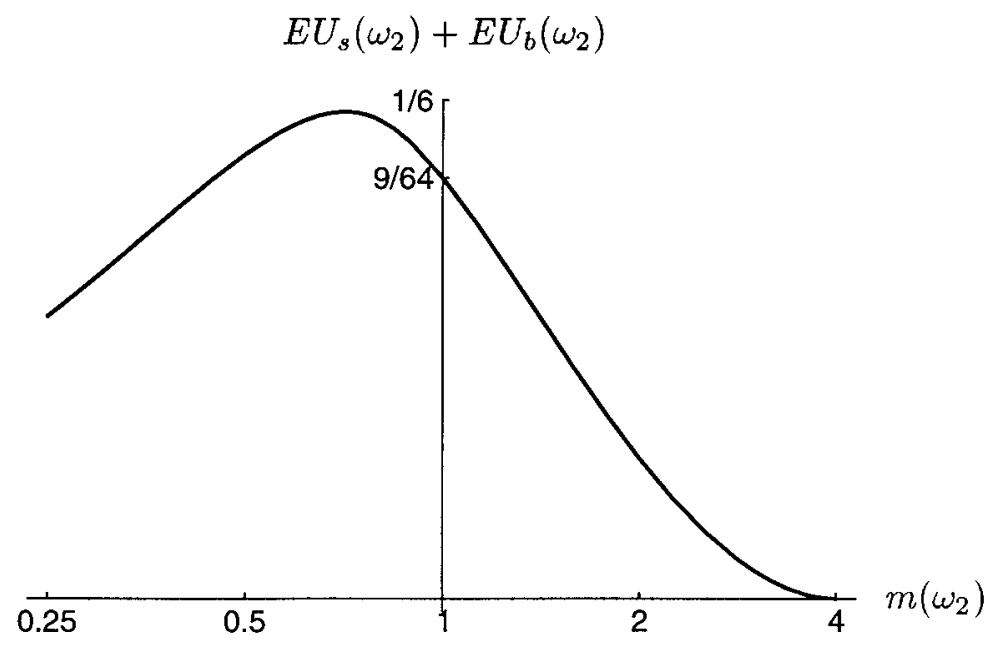

FIG. 5. Total expected utility in state $\omega_{2}$.

then the buyer bids less aggressively and hence there is less trade. If money becomes cheaper (inflation), then the buyer bids more aggressively and the probability of trade increases. However, if money is too cheap (hyperinflation), then the good is sold too often, even when the seller values it more than the buyer. In the extreme case when money is worth next to nothing, the buyer almost always buys the good and hence total expected gains from trade approach zero. This example illustrates how moderate levels of inflation encourage trade, but high levels render the value of money so meaningless that trade becomes chaotic, occurring even when gains are negative.

Interpreted as taking place in time, state $\omega_{1}$ is the status quo; state $\omega_{2}$ is the "transition period" in which the buyer knows about the revaluation but the seller doesn't realize it yet; finally, $\omega_{3}$ is the "stabilization period" in which the revaluation becomes common knowledge. This sequence involves a nominal price increase and a temporary increase in output, as in the Phillips curve. Of course this depends crucially on the particular information and belief asymmetry: perhaps factory owners follow economic news more closely and are closer socially to people in the Federal Reserve, for example (see Cukierman [10]). If money were suddenly worth more instead (deflation), the authority should try to inform the seller and surprise the buyer.

Subjective beliefs are often considered problematic (Harsanyi [15]): for example, Sargent [29, p. 7] notes that "if perceptions were not consistent, then there would exist unexploited utility- or profit-maximizing possibilities within the system." The example here shows that this is true at the 
individual but not at the collective level; subjective beliefs or surprises can help a group exploit more of the possible gains from trade and with appropriate side payments can make everyone better off. Many of the standard objections to subjective beliefs are addressed by Morris [21]; Aumann [2, p. 93] simply notes that specifying subjective priors is simpler than starting with common priors and specifying the private observations which make priors different (Savage's [37] "small worlds" argument). Aumann [4, p. 15] speculates that subjective beliefs have not been much discussed because they are not considered economically relevant; this might change as game theory turns to macroeconomic questions, which emphasize the unexpected. These "philosophical" considerations aside, subjective beliefs naturally arise out of any applied model in which people make mistakes (Brandenburger, Dekel, and Geanakoplos [6]), learn in a heterogeneous environment, or are differentially informed.

\section{CONCLUDING REMARKS}

I should make clear what the model is not about. Firstly, welfare effects do not come from money flows into or out of the model; in each state of the world, every dollar the seller receives comes directly out of the buyer's pocket. Secondly, there are no costs or benefits associated with money itself: it does not cost anything to get money, store money, or redeem it, and there is no special utility from holding money over any other good. There are no liquidity issues or direct transactions costs. The only "friction" is the incomplete information, about each other's valuation and also about money, which necessitates a strategic approach. Thirdly, people are risk-neutral over the uncertainty in money and everything else for that matter. Fourthly, there is no "money illusion": individuals may not be fully informed or have correct priors, but they are fully rational in the sense of maximizing expected utility. Finally, money does not operate here by helping solve a "coordination failure" (for a survey see Silvestre [37]).

Using game theoretic techniques to understand money goes back at lest to the work of Shubik (see Shubik [36]) and has continued in many interesting directions; the most obvious extension of our model would be to include multiple sellers and buyers (as in for example Gresik and Satterthwaite [14]). These techniques have two advantages. The first is that they easily allow descriptions of trade at the level of the individual. The effects of alterations in the trading environment, such as monetary revaluations, can thus be modelled explicitly without resorting to aggregate descriptors such as price or output rigidity. The second is that they allow incomplete information to be modelled very flexibly, not just as a structural feature of the economy but as a policy variable, allowing for example the reeded edge and the Phillips curve to be special cases of the same model. 


\section{APPENDIX}

The following lemma is helpful.

Lemma. Say we have $\Gamma\left(\Omega, \pi_{s}, \pi_{b}, \mathscr{P}_{s}, \mathscr{P}_{b}, m\right)$. Given an event $E \in \mathscr{P}_{s} \wedge$ $\mathscr{P}_{b}$, define $\Gamma\left(E, \pi_{s}^{E}, \pi_{b}^{E}, \mathscr{P}_{s}^{E}, \mathscr{P}_{b}^{E}, m^{E}\right)$, where $\pi_{i}^{E}(\omega)=\pi_{i}(\omega) /\left(\sum_{\omega^{\prime} \in E} \pi_{i}\left(\omega^{\prime}\right)\right)$, $\mathscr{P}_{i}^{E}=\{A \cap E\}_{A \in \mathscr{P}_{i}}$, and $m^{E}(\omega)=m(\omega)$ for $\omega \in E$ and $i \in\{s, b\}$. Also, given $s: \Omega \times[0,1] \rightarrow \mathfrak{R}$ and $b: \Omega \times[0,1] \rightarrow \mathfrak{R}$, define $s^{E}: E \times[0,1] \rightarrow \mathfrak{R}$ and $b^{E}: E \times[0,1] \rightarrow \mathfrak{R}$ as $s^{E}\left(\omega, v_{s}\right)=s\left(\omega, v_{s}\right)$ and $b^{E}\left(\omega, v_{b}\right)=b\left(\omega, v_{b}\right)$ for $\omega \in E$. Then $(s, b)$ in an equilibrium of $\Gamma\left(\Omega, \pi_{s}, \pi_{b}, \mathscr{P}_{s}, \mathscr{P}_{b}, m\right)$ if and only if $\left(s^{E}, b^{E}\right)$ is an equilibrium of $\Gamma\left(E, \pi_{s}^{E}, \pi_{s}^{E}, \mathscr{P}_{s}^{E}, \mathscr{P}_{b}^{E}, m^{E}\right)$ for all events $E \in \mathscr{P}_{s} \wedge \mathscr{P}_{b}$.

Proof. $(\Rightarrow)$ Say that $(s, b)$ is an equilibrium of $\Gamma\left(\Omega, \pi, \mathscr{P}_{s}, \mathscr{P}_{b}, m\right)$ and that there is some $E \in \mathscr{P}_{s} \wedge \mathscr{P}_{b}$ such that $\left(s^{E}, b^{E}\right)$ is not an equilibrium of $\Gamma\left(E, \pi^{E}, \mathscr{P}_{s}^{E}, \mathscr{P}_{b}^{E}, m^{E}\right)$. By definition of equilibrium, either the seller or the buyer gains from deviating. Say the seller gains by deviating: there exists $s^{\prime}: E \times[0,1] \rightarrow \Re$ measurable with respect to $\mathscr{P}_{s}^{E}$ such that $E U_{s}\left(s^{\prime}, b^{E}\right)-E U_{s}\left(s^{E}, b^{E}\right)>0$. If we then define $s^{\prime}: \Omega \times[0,1] \rightarrow \mathfrak{R}$ as

$$
s^{\prime}\left(\omega, v_{s}\right)=\left\{\begin{array}{lll}
s^{\prime}\left(\omega, v_{s}\right) & \text { if } \quad \omega \in E \\
s\left(\omega, v_{s}\right) & \text { if } \quad \omega \in \Omega \backslash E
\end{array}\right.
$$

then $s^{\prime}$ is measurable with respect to $\mathscr{P}_{s}$ ( since $E \in \mathscr{P}_{s} \wedge \mathscr{P}_{b}$ ), and hence is a strategy for the seller. Then we can show that $E U_{s}\left(s^{\prime}, b\right)-E U_{s}(s, b)=$ $E U_{s}\left(s^{\prime}, b^{E}\right)-E U_{s}\left(s^{E}, b^{E}\right)>0$. Hence $(s, b)$ is not an equilibrium of $\Gamma\left(\Omega, \pi, \mathscr{P}_{s}, \mathscr{P}_{b}, m\right)$, which is a contradiction.

$(\Leftarrow)$ Say that $\left(s^{E}, b^{E}\right)$ is an equilibrium of $\Gamma\left(E, \pi^{E}, \mathscr{P}_{s}^{E}, \mathscr{P}_{b}^{E}, m^{E}\right)$ for all events $E \in \mathscr{P}_{s} \wedge \mathscr{P}_{b}$ and $(s, b)$ is not an equilibrium of $\Gamma\left(\Omega, \pi, \mathscr{P}_{s}, \mathscr{P}_{b}, m\right)$. Then either the seller or the buyer gains by deviating. Say the seller gains by deviating to a strategy for the seller $s^{\prime}$, and so $E U_{s}\left(s^{\prime}, b\right)>E U_{s}(s, b)$. Since $\mathscr{P}_{s} \wedge \mathscr{P}_{b}$ partitions $\Omega$, there must be some $E \in \mathscr{P}_{s} \wedge \mathscr{P}_{b}$ such that $\sum_{\omega \in E}$ $\iint_{\left\{\left(v_{s}, v_{b}\right) \in[0,1]^{2}: b\left(\omega, v_{b}\right) \geqslant s\left(\omega, v_{s}\right)\right\}} \pi_{s}(\omega)\left(m(\omega)\left(\left(s^{\prime}\left(\omega, v_{s}\right)+b\left(\omega, v_{b}\right)\right) / 2\right)-v_{s}\right) d v_{s} d v_{b}$ $>\sum_{\omega \in E} \iint_{\left\{\left(v_{s}, v_{b}\right) \in[0,1]^{2}: b\left(\omega, v_{b}\right) \geqslant s\left(\omega, v_{s}\right)\right\}} \pi_{s}(\omega)\left(m(\omega)\left(\left(s\left(\omega, v_{s}\right)+b\left(\omega, v_{b}\right)\right) / 2\right)-\right.$ $\left.v_{s}\right) d v_{s} d v_{b}$. But then it is easy to see that $\left(s^{E}, b^{E}\right)$ is not an equilibrium of $\Gamma\left(E, \pi^{E}, \mathscr{P}_{s}^{E}, \mathscr{P}_{b}^{E}, m^{E}\right)$, since the seller would gain by deviating to $s^{E}$.

Proposition 1. Say we have $\Gamma\left(\Omega, \pi_{s}, \pi_{b}, \mathscr{P}_{s}, \mathscr{P}_{b}, m\right)$. The redemption rule $m$ is neutral if and only if for all $y \in(0, \infty)$, the event $m^{-1}(\{y\}) \subset \Omega$ is common knowledge given $\omega$ for all $\omega \in m^{-1}(\{y\})$.

Proof. $(\Rightarrow)$ It is easy to show that $\left(s^{l}, b^{l}\right)$, where $s^{l}\left(\omega, v_{s}\right)=$ $1 / 4+2 v_{s} / 3$ and $b^{l}\left(\omega, v_{b}\right)=1 / 12+2 v_{b} / 3$, is an equilibrium of $\Gamma\left(\Omega, \pi_{s}, \pi_{b}\right.$, $\left.\mathscr{P}_{s}, \mathscr{P}_{b}, \bar{m}\right)$, where $\bar{m}(\omega)=1$ for all $\omega \in \Omega$. Since $m$ is neutral, by definition of neutrality, $(s, b)$ must be an equilibrium of $\Gamma\left(\Omega, \pi_{s}, \pi_{b}, \mathscr{P}_{s}, \mathscr{P}_{b}, m\right)$, where 
$s\left(\omega, v_{s}\right)=s^{l}\left(\omega, v_{s}\right) / m(\omega)$ and $b\left(\omega, v_{b}\right)=b^{l}\left(\omega, v_{b}\right) / m(\omega)$. Since $(s, b)$ is an equilibrium, $s$ must be measurable with respect to $\mathscr{P}_{s}$. Since all the "variation" in $s$ comes from $m$, we know that $m$ is measurable with respect to $\mathscr{P}_{s}$. Similarly, $m$ is measurable with respect to $\mathscr{P}_{b}$. Hence $m$ is measurable with respect to $\mathscr{P}_{s} \wedge \mathscr{P}_{b}$.

$(\Leftarrow)$ If $m^{-1}(\{y\}) \in \mathscr{P}_{s} \wedge \mathscr{P}_{b}$ for all $y$, then the redemption rule $m$ must be constant over all events $E \in \mathscr{P}_{s} \wedge \mathscr{P}_{b}$. So $m^{E}$ is constant, and say it takes the value $m^{*} \in(0, \infty)$. It is easy to see that $\left(s^{E}, b^{E}\right)$ is an equilibrium of $\Gamma\left(E, \pi_{s}^{E}, \pi_{b}^{E}, \mathscr{P}_{s}^{E}, \mathscr{P}_{b}^{E}, m^{E}\right)$ if and only if $\left(m^{*} s, m^{*} b\right)$ is an equilibrium of $\Gamma\left(E, \pi_{s}^{E}, \pi_{b}^{E}, \mathscr{P}_{s}^{E}, \mathscr{P}_{b}^{E}, \bar{m}\right)$, where $\bar{m}(\omega)=1$ for all $\omega \in E$. By the Lemma, we hence know that $(s, b)$ is an equilibrium of $\Gamma\left(\Omega, \pi_{s}, \pi_{b}, \mathscr{P}_{s}, \mathscr{P}_{b}, m\right)$ if and only if $([s],[b])$ is an equilibrium of $\Gamma\left(\Omega, \pi_{s}, \pi_{b}, \mathscr{P}_{s}, \mathscr{P}_{b}, \bar{m}\right)$, and so $m$ is neutral.

Proposition 2. Say $(s, b)$ is an equilibrium of $\Gamma\left(\Omega, \pi_{s}, \pi_{b}, \mathscr{P}_{s}, \mathscr{P}_{b}, m\right)$, where $\pi_{s}=\pi_{b}$. Then $E U_{s}(s, b)+E U_{b}(s, b) \leqslant 9 / 64$.

Proof. Define a general revelation mechanism $(p, x)$, where $p\left(\omega, v_{s}, v_{b}\right)$ is the probability that the good is transferred from seller to buyer and $x\left(\omega, v_{s}, v_{b}\right)$ is the expected transfer (in terms of utility) from the buyer to the seller. Define the seller's incentive constraints to be $\sum_{\omega \in P_{s}\left(\omega^{\prime}\right)} \pi_{s}(\omega)$ $\int_{0}^{1}\left(x\left(\omega, v_{s}, v_{b}\right)-v_{s} p\left(\omega, v_{s}, v_{b}\right)\right) d v_{b} \geqslant \sum_{\omega \in P_{s}\left(\omega^{\prime}\right)} \pi_{s}(\omega) \int_{0}^{1}\left(x\left(\omega, v_{s}^{\prime}, v_{b}\right)-\right.$ $\left.v_{s} p\left(\omega, v_{s}^{\prime}, v_{b}\right)\right) d v_{b}$ for all $\omega^{\prime} \in \Omega$ and $v_{s}, v_{s}^{\prime} \in[0,1]$; in other words, for any $v_{s}$ and $\omega^{\prime}$, the seller cannot gain by reporting $v_{s}^{\prime}$ instead. Similarly, the buyer's incentive constraints are $\sum_{\omega \in P_{b}\left(\omega^{\prime}\right)} \pi_{b}(\omega) \int_{0}^{1}\left(v_{b} p\left(\omega, v_{s}, v_{b}\right)-\right.$ $\left.x\left(\omega, v_{s}, v_{b}\right)\right) d v_{s} \geqslant \sum_{\omega \in P_{b}\left(\omega^{\prime}\right)} \pi_{b}(\omega) \int_{0}^{1}\left(v_{b} p\left(\omega, v_{s}, v_{b}^{\prime}\right)-x\left(\omega, v_{s}, v_{b}^{\prime}\right)\right) d v_{s}$ for all $\omega^{\prime} \in \Omega$ and $v_{b}, v_{b}^{\prime} \in[0,1]$.

It is easy to show (i.e., the revelation principle) that if $(s, b)$ is an equilibrium of $\Gamma\left(\Omega, \pi_{s}, \pi_{b}, \mathscr{P}_{s}, \mathscr{P}_{b}, m\right)$, then the mechanism $(p, x)$ satisfies the incentive constraints above and yields the same expected utilities, where $p\left(\omega, v_{s}, v_{b}\right)=1$ if $s\left(\omega, v_{s}\right) \leqslant b\left(\omega, v_{b}\right)$ and 0 otherwise, and $x\left(\omega, v_{s}, v_{b}\right)=$ $m(\omega)\left(s\left(\omega, v_{s}\right)+b\left(\omega, v_{b}\right)\right) / 2$ if $s\left(\omega, v_{s}\right) \leqslant b\left(\omega, v_{b}\right)$ and 0 otherwise.

Define a new mechanism $\left(p^{*}, x^{*}\right)$ as $p^{*}\left(v_{s}, v_{b}\right)=\sum_{\omega \in \Omega} \pi(\omega) p\left(\omega, v_{s}, v_{b}\right)$ and $x^{*}\left(v_{s}, v_{b}\right)=\sum_{\omega \in \Omega} \pi(\omega) x\left(\omega, v_{s}, v_{b}\right)$, where $\pi=\pi_{s}=\pi_{b}$. It is easy to check that ex ante expected utilities from this mechanism are the same as in $(p, x)$ above. If we "add up" the seller's incentive constraints above, we get $\sum_{\omega \in \Omega} \pi_{s}(\omega) \int_{0}^{1}\left(x\left(\omega, v_{s}, v_{b}\right)-v_{s} p\left(\omega, v_{s}, v_{b}\right)\right) d v_{b} \geqslant \sum_{\omega \in \Omega} \pi_{s}(\omega) \int_{0}^{1}$ $\left(x\left(\omega, v_{s}^{\prime}, v_{b}\right)-v_{s} p\left(\omega, v_{s}^{\prime}, v_{b}\right)\right) d v_{b}$, or in other words $\int_{0}^{1}\left(x^{*}\left(v_{s}, v_{b}\right)-\right.$ $\left.v_{s} p^{*}\left(v_{s}, v_{b}\right)\right) d v_{b} \geqslant \int_{0}^{1}\left(x *\left(v_{s}^{\prime}, v_{b}\right)-v_{s} p^{*}\left(v_{s}^{\prime}, v_{b}\right)\right) d v_{b}$ for all $v_{s}, v_{s}^{\prime} \in[0,1]$. Similarly, by adding up the buyer's incentive constraints, we get $\int_{0}^{1}$ $\left(v_{b} p^{*}\left(v_{s}, v_{b}\right)-x^{*}\left(v_{s}, v_{b}\right)\right) \quad d v_{s} \geqslant \int_{0}^{1}\left(v_{b} p^{*}\left(v_{s}, v_{b}^{\prime}\right)-x^{*}\left(v_{s}, v_{b}^{\prime}\right)\right) d v_{s}$ for all $v_{b}, v_{b}^{\prime} \in[0,1]$. But these constraints are simply the incentive constraints in the "no policy" case in which there is no money uncertainty. Myerson and 
Satterthwaite (1983) showed that mechanisms which satisfy these constraints have total expected utility less than or equal to $9 / 64$.

Proposition 3. Say we have $\Gamma\left(\Omega, \pi_{s}, \pi_{b}, \mathscr{P}_{s}, \mathscr{P}_{b}, m\right)$, where $\pi_{s}=\pi_{b}=\pi$ and $\mathscr{P}_{s}=\mathscr{P}_{b}$. Then $(s, b)$ is an equilibrium of $\Gamma\left(\Omega, \pi_{s}, \pi_{b}, \mathscr{P}_{s}, \mathscr{P}_{b}, m\right)$ if and only if $(s, b)$ is an equilibrium of $\Gamma\left(\Omega, \pi_{s}, \pi_{b}, \mathscr{P}_{s}, \mathscr{P}_{b}, m^{\text {avg }}\right)$, where $m^{\text {avg }}$ is defined by $m^{\text {avg }}(\omega)=\left(\sum_{\omega^{\prime} \in P_{s}(\omega)} \pi\left(\omega^{\prime}\right) m\left(\omega^{\prime}\right)\right) /\left(\sum_{\omega^{\prime} \in P_{s}(\omega)} \pi\left(\omega^{\prime}\right)\right)$.

Proof. By the Lemma, without loss of generality, we can assume that $\mathscr{P}_{s}=\mathscr{P}_{b}=\{\Omega\}$. Then strategies $s$ and $b$ are constant with respect to $\omega$, and since $\pi_{s}=\pi_{b}=\pi$, we can write expected utilities as

$$
\begin{aligned}
E U_{s}(s, b)= & \iint_{\left\{\left(v_{s}, v_{b}\right) \in[0,1]^{2}: b\left(\omega, v_{b}\right) \geqslant s\left(\omega, v_{s}\right)\right\}} \\
& \times\left(\sum_{\omega \in \Omega} \pi(\omega) m(\omega)\right)\left(\frac{s\left(\omega, v_{s}\right)+b\left(\omega, v_{b}\right)}{2}\right)-v_{s} d v_{s} d v_{b} \\
E U_{b}(s, b)= & \iint_{\left\{\left(v_{s}, v_{b}\right) \in[0,1]^{2}: b\left(\omega, v_{b}\right) \geqslant s\left(\omega, v_{s}\right)\right\}} \\
& \times\left(v_{b}-\left(\sum_{\omega \in \Omega} \pi(\omega) m(\omega)\right) \frac{s\left(\omega, v_{s}\right)+b\left(\omega, v_{b}\right)}{2}\right) d v_{s} d v_{b}
\end{aligned}
$$

which are exactly the expected utilities in the case when money is worth $\sum_{\omega \in \Omega} \pi(\omega) m(\omega)$ with certainty.

\section{REFERENCES}

1. J. Auerbach and B. Crosariol, Microsoft's blockbuster: backed by a $\$ 200$ million blitz, Window 95 is coming to a PC screen near you, in "Boston Globe," (1995), 89.

2. R. J. Aumann, Subjectivity and correlation in randomized strategies, J. Math. Econ. 1 (1974), 67-96.

3. R. J. Aumann, Agreeing to disagree, Ann. Statist. 4 (1976), 1236-1239.

4. R. J. Aumann, Correlated equilibrium as an expression of bayesian rationality, Econometrica 55 (1987), 1-18.

5. A. V. Banerjee and E. S. Maskin, A walrasian theory of money and barter, Quart. J. Econ. 111 (1996), 955-1005.

6. A. Brandenburger, E. Dekel, and J. Geanakoplos, Correlated equilibrium with generalized information structures, Games Econ. Behav. 4 (1992), 182-201.

7. K. Chatterjee and W. Samuelson, Bargaining under incomplete information, Oper. Res. 31 (1983), 835-851.

8. M. S.-Y. Chwe, Culture, circles, and commercials: publicity, common knowledge, and social coordination, Rationality and Society 10 (1998), 47-75.

9. M. S.-Y. Chwe, Believe the hype: Solving coordination problems with television advertising, working paper, University of Chicago, 1988. 
10. A. Cukierman, "Inflation, Stagflation, Relative Prices, and Imperfect Information," Cambridge University Press, Cambridge, UK, 1984.

11. R. G. Doty, "The Macmillan Encyclopedic Dictionary of Numismatics," Macmillan, New York, 1982.

12. M. Friedman, The role of monetary policy, Amer. Econ. Rev. 58 (1968), 1-17.

13. M. Goodfriend, Monetary mystique: secrecy and central banking, J. Monet. Econ. 17 (1986), 63-92.

14. T. A. Gresik and M. A. Satterthwaite, The rate at which a simple market converges to efficiency as the number of traders increases: an asymptotic result for optimal trading mechanisms, J. Econ. Theory 48 (1989), 304-332.

15. J. C. Harsanyi, Games with incomplete information played by Bayesian players, part III. The basic probability distribution of the game, Manage. Sci. 14 (1968), 486-502.

16. L. E. Jones and R. E. Manuelli, Policy uncertainty and informational monopolies: the case of monetary policy, working paper, Managerial Economics and Decision Sciences Kellogg Graduate School of Business, Northwestern University, 1996.

17. W. Leininger, P. B. Linhart, and R. Radner, Equilibria of the sealed-bid mechanism for bargaining with incomplete information, J. Econ. Theory 48 (1989), 63-106.

18. P. B. Linhart, R. Radner, and M. A. Satterthwaite, "Bargaining with Incomplete Information," Academic Press, San Diego, 1992.

19. R. E. Lucas, Jr., Expectations and the neutrality of money, J. Econ. Theory 4 (1972), $103-124$.

20. D. Monderer and D. Samet, Approximating common knowledge with common beliefs, Games Econ. Behav. 1 (1989), 170-190.

21. S. Morris, The common prior assumption in economic theory, Econ. Phil. 11 (1995), 227-253.

22. S. Morris, R. Rob, and H. S. Shin, p-dominance and belief potential, Econometrica 63 (1995), 145-157.

23. R. B. Myerson and M. A. Satterthwaite, Efficient mechanisms for bilateral trading, J. Econ. Theory 29 (1983), 265-281.

24. H. J. O'Gorman, White and black perceptions of radical values, Pub. Opin. Quart. 43 (1979), 48-59.

25. H. J. O'Gorman, The discovery of pluralistic ignorance: an ironic lesson, J. Hist. Behav. Sci. 22 (1986), 333-347.

26. E. Phelps, Introduction: the new microeconomics in employment and inflation theory, in "Microeconomic Foundations of Employment and Inflation Theory" (E. Phelps, Ed.), Norton, New York, 1970.

27. R. Radner and A. Schotter, The sealed-bid mechanism: an experimental study, J. Econ. Theory 48 (1989), 179-220.

28. A. Rubinstein, The electronic mail game: strategic behavior under "almost common knowledge", Amer. Econ. Rev. 79 (1989), 385-391.

29. T. J. Sargent, "Bounded Rationality in Macroeconomics," Clarendon Press, Oxford, 1993.

30. T. J. Sargent, "Rational Expectations and Inflation," second edition, HarperCollins, New York, 1993.

31. M. A. Satterthwaite and S. R. Williams, Bilateral trade with the sealed bid $k$-double auction: existence and efficiency, J. Econ. Theory 48 (1989), 107-133.

32. L. J. Savage, "The Foundations of Statistics," Wiley, New York, 1954.

33. J. Shamir, Pluralistic ignorance revisited: perception of opinion distributions in Israel, Int. J. Pub. Opin. Res. 5 (1993), 22-39.

34. H. S. Shin, Defining a notion of confidence in an economy with differential information, working paper, Department of Economics, University of Southampton, 1995. 
35. H. S. Shin, Comparing the robustness of trading systems to higher-order uncertainty, Rev. Econ. Stud. 63 (1996), 39-59.

36. M. Shubik, A game theoretic approach to the theory of money and financial institutions, in "Handbook of Monetary Economics" (B. M. Friedman and F. H. Hahn, Eds.), North-Holland, Amsterdam, 1990.

37. J. Silvestre, The market-power foundations of macroeconomic policy, J. Econ. Lit. 31 (1993), 105-141.

38. S. Williamson and R. Wright, Barter and monetary exchange under private information, Amer. Econ. Rev. 84 (1994), 104-123. 